\title{
Laparoscopic sacrocolpopexy: impact of the learning curve. Historic retrospective comparative study between two series of 93 and 169 patients
}

\author{
Céline Castellier • Lucie Bresson • Michel Cosson • \\ Jean-Philippe Lucot
}

Received: 31 July 2011 /Accepted: 29 October 2011 /Published online: 23 November 2011

(C) Springer-Verlag 2011

\begin{abstract}
Genital prolapse is one of the most frequent reasons for gynaecologic consultations. Laparoscopic sacrocolpopexy (LSC) became the gold standard since laparoscopy was developed. We retrospectively compared two groups of patients: 82 who undergone LSC from January 1996 to December 2002 (group A) and 169 from January 2002 to December 2009 (group B), always by the same team. Suspension was reinforced with two strips of synthetic mesh. Laparoscopy was performed in 93 women of group A and 169 of group B. They all had symptomatic uterine prolapse. Conversion to laparotomy because of technical difficulties was significantly lower in the second than the first period ( 1 vs. $11, p<0.001)$. We performed less culdoplasty, levator myorrhaphy and Burch colposuspension $(p<0.001)$ but more associated cure of urinary stress incontinence in the second period. Peri-operative complications $(7.3 \%$ vs. $1.8 \%, p=0.006)$, post-operative complications $(21 \%$ vs. $5 \%)$, and surgical length decreased (231 to $191 \mathrm{~min}, p<0.001)$. Six patients $(7 \%)$ in group A had reintervention, $15(9 \%)$ in group B. LSC is a reproducible technique. A learning curve shortens the length of intervention and operative and post-operative complications and rate of conversion to laparotomy.
\end{abstract}

Keywords Laparoscopy · Sacrocolpopexy · Complications . Learning curve

C. Castellier $(\bowtie) \cdot$ L. Bresson • M. Cosson · J.-P. Lucot Pôle de chirurgie gynécologique, Hôpital Jeanne de Flandre, Avenue Eugène Avinée,

59037 Lille Cedex, France

e-mail: celine.castellier@yahoo.fr

\section{Background}

Genital prolapse is one of the most frequent reasons for gynaecological consultation. In their lifetime, women have an $11 \%$ risk to be surgically treated for altered pelvic statics. Prolapse is linked to urinary incontinence in $38 \%$ of cases and one third of patients will have further intervention [1], the risk growing with age. Life is longer, quality of life is better, and women's demands for surgery increase. Prolapse surgery is an anatomical reconstruction but, above all, a functional surgery.

Nowadays, several techniques using several surgical routes are possible to treat prolapse (vaginal, laparotomy and laparoscopy). The operator may freely choose which are according to his experience and his skills, the type of the prolapse, the age of the patient, her characteristics and her wishes. However, the use of one technique over another is still subject to discussion.

Sacrocolpopexy remains the reference in this prolapse surgery. Described by laparotomy by the Huguier and Scali team in 1957 [2, 3], the technique has evolved. It has since been adapted to laparoscopy [4] with gestures now standardised $[5,6]$. Laparoscopic surgery of prolapse with mesh began more than 10 years ago $[7,8]$. Laparoscopy, which is less invasive, allows more precise and complete dissection of the different spaces with more precise view of anatomical landmarks.

In the same way, procedures associated with sacrocolpopexy have changed; Burch has been replaced by suburethral transobturator strips $\left(\mathrm{TVT}^{\circledR}\right)$ and culdoplasty has disappeared.

We wanted to compare two groups of patients treated for prolapse by the same laparoscopic sacrocolpopexy (LSC) technique, the same team, at two different periods. We could 
thus assess the evolution of associated procedures, peri- and post-surgical complications, and rate of re-interventions.

\section{Methods}

\section{Patients}

We realised a retrospective study of patients who had a laparoscopic sacrocolpopexy for genital prolapse, by the same team, from January 1996 to December 2009. There were divided in two groups: group A, 1996-2002 at Paul Gellé maternity ward of Roubaix Hospital and group B: 2002-2009 in medico-surgical gynaecologic service of Hospital Jeanne de Flandre (CHRU, LILLE).

Surgical indication for symptomatic prolapse largely depended on the patient's demand and wishes which were discussed with her. When clinical examination also found urinary incontinence, it was treated in the same surgical time.

\section{Surgical technique}

Keyhole interventions were done under general anaesthesia, in dorsal decubitus, an in Trendelenburg position. Surgical technique used was described by Cosson [9]. Four trocars were used: a 10-mm transumbilical trocar for the laparoscope, two reusable 5-mm trocars inserted lateral to the umbilicus and epigastric vessels on either side, and finally a 10-mm trocar placed in the suprapubic position. Associated procedures, such as supracervical hysterectomy with or without adnexectomy, were performed first, using bipolar coagulation and scissors. The cervix was sectioned with monopolar scissors. After supracervical hysterectomy, the uterus was morcellated using a morcellator (STORZ ${ }^{\circledR}$ ). We dissected the vaginal fornices by mobilising the bladder anteriorly and the rectum and sigmoid posteriorly. Anterior and posterior lengths of non-resorbable synthetic mesh were sutured to the vaginal wall. When conservation of the uterus was required, the anterior strip was Y-shaped, its two arms going through the broad ligament before reaching the sacral promontory. The peritoneum overlying the sacrum was opened, and the areolar tissue was carefully dissected to expose the anterior longitudinal sacral ligament. Two permanent $\mathrm{O}$ sutures were placed in the anterior longitudinal sacral ligament to suspend the mesh. Tension was applied via extra-abdominal knots and checked by the surgeon. The mesh was then trimmed and implanted by closing the peritoneum with a resorbable continuous nonlocking running suture. Meshes used were made of polyester (PARIETEX ${ }^{\circledR}$ ) or of knitted polypropylene monofilament (SURGIPRO ${ }^{\circledR}$, GYNEMESH ${ }^{\circledR}$ ).

When necessary, a BURCH colposuspension was performed. The retropubic space was dissected transperitoneally after opening the peritoneum. The ureterovaginal junction and Cooper's ligament were exposed. One non-resorbable suture was placed on either side of the urethra in the vaginal wall, taking care not to transfix the vagina, and suspended on Cooper's ligament. The peritoneum was then closed with resorbable 2/0 using a running suture. Burch colposuspension was performed except in cases of previous surgery for incontinence without recurrence.

Vaginal myorrhaphy of the levator muscles was carried out as in Huguier's description [10]. A 4-cm longitudinal incision of the vaginal mucosa was made over the posterior fourchette. The edges of the incision were held with Allis clamps and the peri-rectal fascia was dissected, revealing the margins of the levator ani. A heavy number 1 absorbable synthetic suture was passed through the levator ani near the posterior fourchette. The posterior vaginal wall was closed with a resorbable running suture. Myorrhaphy of the levator muscles was performed when clinically indicated.

Urinary incontinence was cured with suburethral strips $\left(\mathrm{TVT}^{\circledR}, \mathrm{TVT}^{\circledR} \mathrm{O}^{\circledR}\right)[11,12]$. With the patient in lithotomy position, suburethral vaginal wall was infiltrated with xylocain. After a medial incision, we dissected laterally to ischiopubic ramus. The obturator membrane was perforated with scissors. The mesh was then placed and tension was regulated. Vaginal closure was effected with a running suture of resorbable thread 3/0.

Data were stored retrospectively in patient's files. Operation length was estimated on laparoscopic time only. Patients with concomitant laparoscopic rectopexy were excluded from the study.

Statistical analysis was realised with Excel Microsoft and Epi-Info (6.4 version). Student's $t$ test was used to analyse quantitative variables. Qualitative variables were analysed with $\chi^{2}$ test, odds ratio or bilateral Fischer's test for values inferior to 5 . Results are considered significant when $p<0.005$.

\section{Findings}

During the period of the study, 93 patients underwent surgery in group A (1996-2002) and 169 in group B (2002-2009). The characteristics of patients and their antecedents are summed up in Table 1 . The only significant difference is the women's age which is higher in group B. History of hysterectomy and cure of prolapse are not significantly different between the two groups.

Associated procedures with laparoscopic sacrocolpopexy are detailed in Table 2. There is a significant decrease of culdoplasties and transvaginal myorrhaphy of elevators. Burch's colposuspension was replaced by synthetic suburethral strips. Indications of curing urinary incontinence 
Table 1 Characteristics of patients with their main gynaecologic surgical antecedents

NB. Some patients had several interventions for prolapse and/or urinary incontinence and several procedures were sometimes concomitant

$N A$ not applicable, BMI body mass index

\begin{tabular}{lllll}
\hline & $\begin{array}{l}\text { Group A } \\
N=82\end{array}$ & $\begin{array}{l}\text { Group B } \\
N=168\end{array}$ & $p$ value & $\begin{array}{l}\text { Odds ratio } \\
\text { (IC at 95\%) }\end{array}$ \\
\hline Age & $47 \pm 8.6$ & $51 \pm 8.6$ & $<0.001$ & NA \\
BMI & $25 \pm 5.0$ & $24 \pm 3.9$ & 0.25 & NA \\
Parity & $3.2 \pm 1.9$ & $2.8 \pm 1.4$ & 0.05 & NA \\
Menopausal & $20(24 \%)$ & $60(36 \%)$ & 0.07 & $0.58(0.31-1.09)$ \\
Substitutive hormonal treatment & $9(11 \%)$ & $11(7 \%)$ & 0.23 & $1.76(0.64-4.82)$ \\
Surgical gynaecologic history & $29(35 \%)$ & $41(24 \%)$ & 0.07 & $1.69(0.92-3.13)$ \\
Cure of prolapse & $7(9 \%)$ & $21(13 \%)$ & 0.35 & $0.65(0.24-1.72)$ \\
Cure of urinary incontinence & $7(9 \%)$ & $15(9 \%)$ & 0.92 & $0.95(0.34-2.62)$ \\
Hysterectomy & $9(11 \%)$ & $13(8 \%)$ & 0.40 & $1.47(0.55-3.88)$ \\
\hline
\end{tabular}

remain stable at $9 \%$ in both study periods. Mean surgical length is significantly shorter, 231 to $191 \mathrm{~min}(p<0.001)$. Hospitalisation length remains identical in the two groups: $3.2 \pm 1.5$ days in group A vs. $3.0 \pm 1.1$ days in group B $(p=0.21)$.

Post-surgical complications are shown in Table 3. There was no mortality or major peri-operative complication. Post-surgical complications did not decrease enough to be significant $(7.3 \%$ in group $\mathrm{A}$ and $1.8 \%$ in group $\mathrm{B}, p=$ 0.06). Most frequent complication was bladder injury. Diagnosis was always made during intervention, with immediate laparoscopic suture and permanent urinary catheterization for 7 days. After-effects were straightforward. In group A, bladder was wounded when threading the needle of retropubic TVT ${ }^{\circledR}$. Diagnosis was achieved by cystoscopy, the needle removed then replaced without further complication. A vaginal lesion happened at time of dissection in group B. Laparoscopic suture, then fixing of a polypropylene mesh, was straightforward without infection or prosthetic exposure. Omental haematoma was noted when sigmoid was suspended to abdominal wall. The after- effects were straightforward. Subcutaneous emphysema did not prevent laparoscopy.

Laparotomy conversion rates were significantly different between the two groups, from $12 \%$ to $0.6 \%$. In group A, indications of 11 laparoconversions were adhesions (four cases), hypercapnia (three cases), difficult access to promontory (two cases), or bleeding (two cases). In group $\mathrm{B}$, the only conversion was due to adhesions.

Early post-surgical complications were four times less frequent in group B (5\%) than in group A, $p<0001$ (Table 4.). These complications were mainly lower urinary tract infections. Their frequency in the two periods changed from $15 \%$ to $4 \%$. In group A, we had two haematomas, one in Retzius space was surgically drained and another was medically treated. Two women had a urinary retention, while re-intervention and section of TVT strip was necessary in one case. In group B, three haematomas were seen at trocar port, one needed a re-intervention for drainage. All in all, two patients in group A and one in group B had a re-intervention for early post-surgical complications.
Table 2 Procedures associated with laparoscopic sacrocolpopexy

\begin{tabular}{|c|c|c|c|c|}
\hline & $\begin{array}{l}\text { Group A } \\
N=82\end{array}$ & $\begin{array}{l}\text { Group B } \\
N=168\end{array}$ & $p$ value & $\begin{array}{l}\text { Odds ratio } \\
\text { (IC at } 95 \% \text { ) }\end{array}$ \\
\hline Supracervical hysterectomy & $57(70 \%)$ & $100(60 \%)$ & 0.13 & $1.55(0.85-2.83)$ \\
\hline Adnexectomy & $26(32 \%)$ & $72(43 \%)$ & 0.09 & $0.62(0.34-1.12)$ \\
\hline Culdoplasty & $67(82 \%)$ & $42(25 \%)$ & $<0.001$ & $13(6.62-27.47)$ \\
\hline Posterior perineorraphy & $36(44 \%)$ & 0 & $<0.001$ & NA \\
\hline Burch & $45(55 \%)$ & 0 & $<0.001$ & NA \\
\hline TVT-O ${ }^{\circledR}$ & 0 & $57(34 \%)$ & $<0.001$ & NA \\
\hline $\mathrm{TVT}^{\circledR}$ & $4(5 \%)$ & $1(0,6 \%)$ & 0.002 & $8.56(0.88-205)$ \\
\hline Mini-Arc ${ }^{\mathbb{R}}$ & 0 & $1(0,6 \%)$ & & \\
\hline Tubal ligation & $2(2 \%)$ & $8(5 \%)$ & 0.38 & $0.50(0.07-2.62)$ \\
\hline Perineoplasty & 0 & $2(1.2 \%)$ & & \\
\hline Anal sphincteroplasty (Musset) & $2(2 \%)$ & 0 & & \\
\hline Richter & $1(1 \%)$ & 0 & & \\
\hline
\end{tabular}


Table 3 Peri-surgical complications

\begin{tabular}{lllll}
\hline & $\begin{array}{l}\text { Group A } \\
N=82\end{array}$ & $\begin{array}{l}\text { Group B } \\
N=168\end{array}$ & $p$ value & $\begin{array}{l}\text { Odds ratio } \\
\text { (IC at 95\%) }\end{array}$ \\
\hline $\begin{array}{l}\text { Total (except } \\
\text { laparoconversion) }\end{array}$ & $6(7.3 \%)$ & $4(1.8 \%)$ & 0.06 & $3.24(0.78-14)$ \\
$\begin{array}{l}\text { Bladder injury } \\
\begin{array}{l}\text { Subcutaneous } \\
\text { emphysema }\end{array}\end{array}$ & 3 & 1 & & \\
$\begin{array}{l}\text { Vaginal breach } \\
\text { Omental haematoma }\end{array}$ & 0 & 1 & & \\
Laparoconversion & $11(12 \%)$ on 93 patients & $1(0,6 \%)$ on 169 patients & $<0.001$ & $22(3.15-971)$ \\
\hline
\end{tabular}

Table 5 gives the detail of long-term re-intervention (secondary complications, relapse). The global rate of longterm re-interventions is similar in both groups, around $8 \%$.

The rate of prosthetic exposure was identical in both groups, around 3\%. They were only polyester meshes. In group A, three cases of vaginal exposure of sacrocolpopexy mesh were systematically medically treated before reintervention. In one case, mesh had been fixed by clips, which were taken away as well as exposed mesh. In group $\mathrm{B}$, two posterior prosthetic exposures were mentioned. In the first case, diagnosis was made at post-surgical consultation and resection realised at 2 months. In the other case, the diagnosis of exposure was achieved very early, and conservative treatment was tried first, but infection at 4 months imposed prosthetic resection.

Otherwise, there were three cases of vaginal exposure of TVT-O ${ }^{\circledR}$ mesh in 41 patients of group B. Two patients $(6 \%)$ had re-intervention at 2 months and resection of exposed strip.

There were, only in group B, three re-interventions for prolapse: two sacrocolpopexies by laparotomy, one subvesical mesh by vaginal route according to $\operatorname{PROLIFT}^{\circledR}$ technique and one antefixation of the uterus with partial cervical resection. One patient had two re-interventions (sacrocolpopexy by laparotomy then uterine antefixation).

Re-intervention for urinary incontinence remained around $4 \%$ in the two groups. These re-interventions were carried out after de novo urinary incontinence, significant pre-existing urinary incontinence more important after laparoscopic sacrocolpopexy, or relapse in patients who already had a cure of urinary incontinence.

Only one patient from group B had a hysterectomy for menorrhagia at 34 months of LSC.

\section{Discussion}

Many authors have published papers on keyhole surgery and laparoscopic sacrocolpopexy; very few have followed up chronologic analysis of results in the same team. To our knowledge, only Claerhout fixed at 60, the number of LSC necessary to improve the learning curve, guided by the rate of laparotomy conversion and the number of peri-surgical complications [13]. Akladios saw a significant reduction of intervention length after around 20 procedures [14]. These data are important as certain publications include initial phase of this learning curve and so overestimate complications and may limit indications of a technique. Our aim was to compare two consecutive periods in the same team. The limit between the two periods is the time when the surgical team moved from one hospital to another. The judgement criteria to evaluate the control of this technique were the rate of conversion to laparotomy and the peri- and early post-surgical complications. Long-term anatomic and functional results are also probably highly relevant in this analysis, this surgery being functional. One of our limitations
Table 4 Early post-surgical complications

\begin{tabular}{lllll}
\hline & $\begin{array}{l}\text { Group A } \\
N=82\end{array}$ & $\begin{array}{l}\text { Group B } \\
N=168\end{array}$ & $p$ value & $\begin{array}{l}\text { Odds ratio } \\
\text { (IC at 95\%) }\end{array}$ \\
\hline Early post-surgical complications & $17(21 \%)$ & $9(5 \%)$ & $<0.001$ & $4.62(1.83-12)$ \\
Lower urinary tract infection & $12(15 \%)$ & $6(4 \%)$ & & \\
Haematoma & 2 & 0 & \\
Urinary retention & 2 & 0 & \\
Thromboembolic complication & 1 & 0 & & \\
Haematoma at trocar port & 0 & 3 & 0.25 & $4.14(0.21-247)$ \\
Re-intervention for early complication & $2(2.4 \%)$ & $1(0.6 \%)$ & & \\
\hline
\end{tabular}


Table 5 Late re-interventions

\begin{tabular}{lllll}
\hline & $\begin{array}{l}\text { Group A } \\
N=82\end{array}$ & $\begin{array}{l}\text { Group B } \\
N=168\end{array}$ & $p$ value & $\begin{array}{l}\text { Odds ratio } \\
\text { (IC at 95\%) }\end{array}$ \\
\hline Vaginal exposure of sacrocolpopexy mesh & $3(3.7 \%)$ & $\begin{array}{l}2(1.2 \%) \\
2 \text { on } 41 \text { patients }\end{array}$ & 0.33 & $3.13(0.35-38)$ \\
Vaginal exposure of TVT-O ${ }^{\circledR}$ mesh & - & $3(1.7 \%)$ & 0.55 & NA \\
$\begin{array}{l}\text { Prolapse (relapse or de novo) } \\
\text { Stress urinary incontinence }\end{array}$ & 0 & $7(3.7 \%)$ & 1 & $0.87(0.14-3.96)$ \\
among which a patient with TVT-O ${ }^{\circledR}$ & - & 1 & & \\
Menorrhagias of remaining uterus & 0 & 1 & 0.67 & $0.81(0.27-2.33)$ \\
Total of re-interventions & $6(7 \%)$ & $15(9 \%)$ & & \\
\hline
\end{tabular}

is probably the consecutive evaluation with different standback in both groups. We could not use retrospectively international classification POP-Q, which was proposed in 1996 by Bump [15].

The rate of laparotomy conversion decreased greatly from $12 \%$ to $0.6 \%$. These rates are similar in literature $(0-11 \%)$ as well as reasons for conversion (adhesions, difficult access to promontory and hypercapnia) [7, 8, 16-18]. This may be due to better mastery and standardisation of techniques for surgeons but also anaesthetists and all the operating staff $[5,6]$. Hypercapnia and difficult access to the promontory are no more an indication for conversion in group B. This may also be due to better selection of patients: vaginal route immediately chosen in case of surgical antecedent or foreseeable surgical difficulties. In case of difficult access to promontory, alternative techniques, such as Dubuisson's, with lateral suspension, will be used which avoids laparotomy conversion and gives good anatomic results [19].

Peri-surgical complications are significantly less frequent in the more recent group, $1.8 \%$ vs. $7.3 \%$ in group A. This may be compared to the rates reported in the literature between $2.2 \%$ and $17.4 \%[18,20-25]$. Bladder wounding is the most frequent complication: $0.8-3 \%$ in our study vs. $1-7 \%$ in literature [8, 9, 18-21, 26-31]. Diagnosis was always made during intervention with immediate suture and simple aftereffects. Certain authors report rectal or vaginal wounding [8, $9,18,32]$. Certain technical devices such as a vaginal valve may allow easier vaginal dissection and reduce surgical risk. After vaginal injury, a polypropylene mesh seems imperative to limit ulterior risk of infection. We have had no major complications in both study periods. Since 2009, we had noted only once a wound of left common iliac vein when dissecting promontory. An emergency laparotomy and a suture by a vascular surgeon allowed to control bleeding (haemorrhage of nearly $3.5 \mathrm{~L}$ ). Follow-up was straightforward. Sacrocolpopexy was not realised and the cure of prolapse by vaginal route was done later.

Post-surgical complications were significantly divided into four. They were essentially lower urinary tract infections with probably multifactorial genesis. One limita- tion of our study is its retrospective character. Certain complications may not have been written up in files or only when the team began this study. In group A, one haematoma of Retzius space was probably linked to Burch's intervention associated. Evolution to suburethral strips limits this risk, which is still non-existent with retropubic route [33]. Other complications are reported in literature such as small intestine occlusion sometimes imposing digestive resection $[8,21,28]$. For us, it seems of utmost importance to peritonize the mesh and suture aponeurosis for trocars superior to $10 \mathrm{~mm}$ to limit this risk.

Our rate of early post-surgical complications decreased from $2.4 \%$ to $0.6 \%$, but not in a significant way $(p=0.25)$, similar to Ganatra's review who demonstrated an average rate of $1.6 \%$ [17]. There was a slight increase in re-interventions for prolapse relapse, without statistical significance (0-1.7\%, NS). Patients were treated by an experienced senior in $90 \%$ in group A vs. 75\% in group B. This slight difference of relapse might be explained by the learning curve of operators. Our results are similar to those found in literature: $4 \%$ in our team in 2002 and $6.2 \%$ for Ganatra [9, 17].

Average surgery length was reduced from 213 to $191 \mathrm{~min}$, slightly superior to literature data (average, $158 \mathrm{~min}$; extremes, 96-286 min) [17]. However, it is difficult to determine precisely the surgical duration, as there are associated procedures. For example, subtotal hysterectomy, very often performed by our team, lasts 30 to $60 \mathrm{~min}$ (hysterectomy and dissection). If our interventions become shorter, that may be due to better surgical technique but also to technical devices and more efficient material (electrocoagulation techniques, needle holder, knot pushers, etc.). Akladios showed a significant reduction of surgery length for each surgeon after around 20 procedures [14]. Our results seem to show that time saving seemed to last longer with more significant techniques even if indications were extended and certain surgeons of the second group were beginning their training experience. These conclusions may come from a fellowship teaching and new devices that make learning shorter.

These conclusions, learning from colleagues and quitting certain procedures (such as culdoplasty or Burch), may 
also explain why surgical times were reduced between the two groups.

\section{Conclusion}

Our study shows that LSC technique can be reproduced with a low rate of complications. There is, though, a learning curve with significant impact on length of interventions, rate of conversion to laparotomy, and peri- and post-surgical complications. The threshold seems quite high since we saw a real difference after the 93 first cases. This parameter must be considered when analysing the results of publications not to overestimate complications. We might also think on the ways to teach these surgical techniques to young doctors, who need to master these techniques

Conflicts of interest The authors report no conflicts of interest. The authors alone are responsible for the content and writing of the paper.

\section{References}

1. Olsen AL, Smith VJ, Bergstrom JO, Colling JC, Clark AL (1997) Epidemiology of surgically managed pelvic organ prolapse and urinary incontinence. Obstet Gynecol 89(4):501-506. doi:10.1016/S0029-7844(97)00058-6

2. Ameline A, Huguier J (1957) Posterior suspension to the lumbosacral disk; abdominal method of replacement of the utero-sacral ligaments. Gynecol Obstet (Paris) 56(1):94-98

3. Huguier J, Scali P (1958) Posterior suspension of the genital axis on the lumbosacral disk in the treatment of uterine prolapse. Presse Med 66(35):781-784

4. Nezhat C, Nezhat F (1992) Operative laparoscopy (minimally invasive surgery): state of the art. J Gynecol Surg 8(3):111-141

5. Wattiez A, Boughizane S, Alexandre F, Canis M, Mage G, Pouly JL, Bruhat MA (1995) Laparoscopic procedures for stress incontinence and prolapse. Curr Opin Obstet Gynecol 7(4):317-321

6. Wattiez A, Canis M, Mage G, Pouly JL, Bruhat MA (2001) Promontofixation for the treatment of prolapse. Urol Clin North Am 28(1):151-157

7. Cosson M, Bogaert E, Narducci F, Querleu D, Crepin G (2000) Laparoscopic sacral colpopexy: short-term results and complications in 83 patients. J Gynecol Obstet Biol Reprod (Paris) 29(8):746-750

8. Cheret A, Von Theobald P, Lucas J, Dreyfus M, Herlicoviez M (2001) Laparoscopic promontofixation feasibility study in 44 patients. J Gynecol Obstet Biol Reprod (Paris) 30(2):139-143

9. Cosson M, Rajabally R, Bogaert E, Querleu D, Crepin G (2002) Laparoscopic sacrocolpopexy, hysterectomy, and burch colposuspension: feasibility and short-term complications of 77 procedures. JSLS 6(2):115-119

10. Huguier J (1957) [Posterior colpo-perineo-myorraphy]. Bull Fed Soc Gynecol Obstet Lang Fr 9(1):28-31, discussion 31-24

11. de Leval J (2003) Novel surgical technique for the treatment of female stress urinary incontinence: transobturator vaginal tape inside-out. Eur Urol 44(6):724-730

12. Ulmsten U, Petros P (1995) Intravaginal slingplasty (IVS): an ambulatory surgical procedure for treatment of female urinary incontinence. Scand J Urol Nephrol 29(1):75-82
13. Claerhout F, De Ridder D, Roovers JP, Rommens H, Spelzini F, Vandenbroucke V, Coremans G, Deprest J (2009) Medium-term anatomic and functional results of laparoscopic sacrocolpopexy beyond the learning curve. Eur Urol 55(6):1459-1467. doi:10.1016/j.eururo.2008.12.008

14. Akladios CY, Dautun D, Saussine C, Baldauf JJ, Mathelin C, Wattiez A (2010) Laparoscopic sacrocolpopexy for female genital organ prolapse: establishment of a learning curve. Eur J Obstet Gynecol Reprod Biol 149(2):218-221. doi:10.1016/j.ejogrb.2009. 12.012

15. Bump RC, Mattiasson A, Bo K, Brubaker LP, DeLancey JO, Klarskov P, Shull BL, Smith AR (1996) The standardization of terminology of female pelvic organ prolapse and pelvic floor dysfunction. Am J Obstet Gynecol 175(1):10-17

16. Nezhat CH, Nezhat F, Nezhat C (1994) Laparoscopic sacral colpopexy for vaginal vault prolapse. Obstet Gynecol 84(5):885-888

17. Ganatra AM, Rozet F, Sanchez-Salas R, Barret E, Galiano M, Cathelineau X, Vallancien G (2009) The current status of laparoscopic sacrocolpopexy: a review. Eur Urol 55(5):10891103. doi:10.1016/j.eururo.2009.01.048

18. Bui C, Ballester M, Chereau E, Guillo E, Darai E (2010) Functional results and quality of life of laparoscopic promontofixation in the cure of genital prolapse. Gynecol Obstet Fertil 38 (10):563-568. doi:10.1016/j.gyobfe.2010.06.001

19. Dubuisson JB, Jacob S, Chapron C, Fauconnier A, Decuypere F, Dubernard G (2002) Laparoscopic treatment of genital prolapse: lateral utero-vaginal suspension with 2 meshes. Results of a series of 47 patients. Gynecol Obstet Fertil 30(2):114-120

20. Antiphon P, Elard S, Benyoussef A, Fofana M, Yiou R, Gettman M, Hoznek A, Vordos D, Chopin DK, Abbou CC (2004) Laparoscopic promontory sacral colpopexy: is the posterior, recto-vaginal, mesh mandatory? Eur Urol 45(5):655-661. doi:10.1016/j.eururo.2004.01.004

21. Rozet F, Mandron E, Arroyo C, Andrews H, Cathelineau X, Mombet A, Cathala N, Vallancien G (2005) Laparoscopic sacral colpopexy approach for genito-urinary prolapse: experience with 363 cases. Eur Urol 47(2):230-236. doi:10.1016/j.eururo.2004.08.014

22. Rivoire C, Botchorishvili R, Canis M, Jardon K, Rabischong B, Wattiez A, Mage G (2007) Complete laparoscopic treatment of genital prolapse with meshes including vaginal promontofixation and anterior repair: a series of 138 patients. J Minim Invasive Gynecol 14(6):712-718. doi:10.1016/j.jmig.2007.06.017

23. Agarwala N, Hasiak N, Shade M (2007) Laparoscopic sacral colpopexy with Gynemesh as graft material-experience and results. J Minim Invasive Gynecol 14(5):577-583. doi:10.1016/j. jmig.2007.03.005

24. Misrai V, Chartier-Kastler E, Cour F, Mozer P, Almeras C, Richard F (2006) Surgical management of chronic refractory pain after TVT treatment for stress urinary incontinence. Prog Urol 16(3):368-371

25. North CE, Ali-Ross NS, Smith AR, Reid FM (2009) A prospective study of laparoscopic sacrocolpopexy for the management of pelvic organ prolapse. BJOG 116(9):1251-1257. doi:10.1111/j.1471-0528.2009.02116.x

26. Weng SS, Liu CY (2008) Laparoscopic pelvic floor repair using polypropylene mesh. Taiwan J Obstet Gynecol 47(3):312-317. doi:10.1016/S1028-4559(08)60130-8

27. Descargues G, Collard P, Grise P (2008) Surgical management of pelvic organ prolapse in women: laparoscopic or vaginal sacrocolpopexy? Gynecol Obstet Fertil 36(10):978-983. doi:10.1016/j.gyobfe.2008.05.007

28. Ross JW, Preston M (2005) Laparoscopic sacrocolpopexy for severe vaginal vault prolapse: five-year outcome. J Minim Invasive Gynecol 12(3):221-226. doi:10.1016/j.jmig.2005.03.017

29. Gadonneix P, Ercoli A, Salet-Lizee D, Cotelle O, Bolner B, Van Den Akker M, Villet R (2004) Laparoscopic sacrocolpopexy with two separate meshes along the anterior and posterior vaginal walls 
for multicompartment pelvic organ prolapse. J Am Assoc Gynecol Laparosc 11(1):29-35

30. Sarlos D, Brandner S, Kots L, Gygax N, Schaer G (2008) Laparoscopic sacrocolpopexy for uterine and post-hysterectomy prolapse: anatomical results, quality of life and perioperative outcome - a prospective study with 101 cases. Int Urogynecol J Pelvic Floor Dysfunct 19 (10):1415-1422. doi:10.1007/s00192-008-0657-0

31. Higgs PJ, Chua HL, Smith AR (2005) Long term review of laparoscopic sacrocolpopexy. BJOG 112(8):1134-1138. doi:10.1111/ j.1471-0528.2005.00646.x
32. Bruyere F, Rozenberg H, Abdelkader T (2001) Laparoscopic sacral colpopexy: an attractive approach for prolapse repair. Prog Urol 11(6):1320-1326

33. Novara G, Artibani W, Barber MD, Chapple CR, Costantini E, Ficarra V, Hilton P, Nilsson CG, Waltregny D (2010) Updated systematic review and meta-analysis of the comparative data on colposuspensions, pubovaginal slings, and midurethral tapes in the surgical treatment of female stress urinary incontinence. Eur Urol 58(2):218-238. doi:10.1016/j.eururo. 2010.04.022 